\title{
Water Movement in Mulched Beds in Rocky Soils of Miami-Dade County ${ }^{1}$
}

\section{David Studstill, Eric Simonne, Teresa Olcz
Summary and Implications for Irrigation}

The drip tape flow rates selected in this study (20 to $35 \mathrm{gal} / 100 \mathrm{ft} / \mathrm{hr}$ ) cover the high- to medium-flow rate range. Emitter spacings used by the vegetable industry were also similar to those used in this trial (4- to 12-inch). Based on our results, flow rate had no effect on the wetted zone of this rocky soil possibly because of shallow soil depth (7 to 10 inches) and high soil heterogeneity. Optimal emitter spacing for uniform moisture was 8 inches. The soil depth used in this study ( 7 to 10 inches) is representative of depth in the area. In some fields, the root zone may be even smaller. These results support the practice of using short irrigation events (1 to 2 hrs.) for the application of water and fertilizer to vegetable crops grown on calcareous soil.

\section{Importance of Soil Water Redistribution in Rocky Soils}

In Miami-Dade county, approximately 40,000 acres of vegetables are grown on both calcareous and rocky soils (Degner et al., 2001). These soils are characterized by very low nutrient and water holding capacity, an alkaline $\mathrm{pH}$ in the 7.4-8.4 range, and levels of calcium carbonate $\left(\mathrm{CaCO}_{3}\right)$ ranging from $30 \%$ to $94 \%$ ( $\mathrm{Li}, 2001)$. Soil profiles of rocky soils appear as an approximately 10-inch-thick layer of crushed limestone particles over the porous limestone bedrock. In shallow soils with high water table ( 2 to $4 \mathrm{ft}$ deep), frequent applications of water and nutrients are needed to ensure rapid growth and economical yields of vegetable crops.

Scheduling irrigation for vegetables typically consists of knowing when to irrigate and how much water to apply to satisfy crop water needs, maintain soil water tension between field capacity and $15 \mathrm{kPa}$ in the root zone, and prevent nutrient leaching (Simonne et al., 2004). Irrigation scheduling requires a target water amount adjusted to weather conditions and crop age, a measure of soil moisture, a method to account for rainfall contribution to soil moisture, and a rule for splitting irrigation. Tensiometers may be used to measure soil water tension in calcareous soils (Olczyk et al., 2002). Splitting irrigation is needed

1. This document is HS1059, one of a series of the Horticultural Sciences Department, Florida Cooperative Extension Service, Institute of Food and Agricultural Sciences, University of Florida. Original publication date March, 2006. Visit the EDIS Web Site at http://edis.ifas.ufl.edu.

2. D.W. Studstill, biologist, E.H. Simonne, associate professor, Horticultural Sciences Department; Teresa Olczyk, Extension Agent, Commercial Ag./Vegetables, Miami-Dade Cooperative Extension; Rafael Muñoz-Carpena, Assistant Professor, Hydrology, Department of Agricultural and Biological Engineering, Cooperative Extension Service, Institute of Food and Agricultural Sciences, University of Florida, Gainesville, 32611.

Disclaimer: Trade names are mentioned for educational purposes and to acknowledge the type of the drip tapes used and do not constitute an endorsement of these products over others of similar characteristics.

The Institute of Food and Agricultural Sciences (IFAS) is an Equal Opportunity Institution authorized to provide research, educational information and other services only to individuals and institutions that function with non-discrimination with respect to race, creed, color, religion, age, disability, sex, sexual orientation, marital status, national origin, political opinions or affiliations. U.S. Department of Agriculture, Cooperative Extension Service, University of Florida, IFAS, Florida A. \& M. University Cooperative Extension Program, and Boards of County Commissioners Cooperating. Larry Arrington, Dean 
when the volume of irrigation exceeds the amount of water that can be stored in the root zone (Clark and Smajstrla, 1993). In practice, splitting irrigation has to be a compromise between two constraints. On one side, frequent and short irrigations are less likely to leach soluble nutrients below the root zone. On the other side, frequent and short irrigations waste water and reduce irrigation uniformity because a large portion of the irrigation cycle is used for system charge and flush. Also, each irrigation cycle has to deliver enough water to completely wet the soil between two adjacent emitters to maintain crop uniformity, especially when the plants are small. In this context, automatic irrigation systems based on soil moisture are a good alternative to traditional irrigation scheduling methods (Munoz-Carpena and Dukes, 2005).

The amount of water that can be stored in the root zone can be assessed by visualizing water movement in the soil using soluble dye (German-Heins and Flury, 2000; Simonne et al., 2003). In this project, blue dye and controlled irrigation conditions were used to visualize and interpret distribution, not chemical movement, of wetting patterns of different drip tapes on a rocky soil of south Miami-Dade county where vegetable crops are typically grown. The main objectives were to (1) describe the shape of the wetted zone for several water volumes applied through drip irrigation, (2) determine vertical, lateral and longitudinal movements of irrigation for increasing water volumes, (3) quantify the relative volume of the wetted raised bed, and (4) provide guidelines for splitting irrigation.

\section{A New Way of Looking at Water Redistribution in the Field}

A dye test was conducted at the Tropical Research and Education Center (TREC), in Homestead, on 14 Oct., 2003 on a 7- to 10-inch-deep Krome very gravelly loam soil. Before the day of the test, 150-ft-long raised beds were formed, and drip tape and polyethylene mulch were laid. Treatments were four drip-tape types (Table 1) and four irrigation durations (1, 2, 3, and $4 \mathrm{hrs})$. Each bed received a different drip tape. The irrigation system consisted of a well, pump, back-flow prevention device, fertilizer injector (model DI16-11, Dosatron, Clearwater, FL), 150-mesh screen filter, 10 psi pressure regulator, and drip tape (Fig. 1).

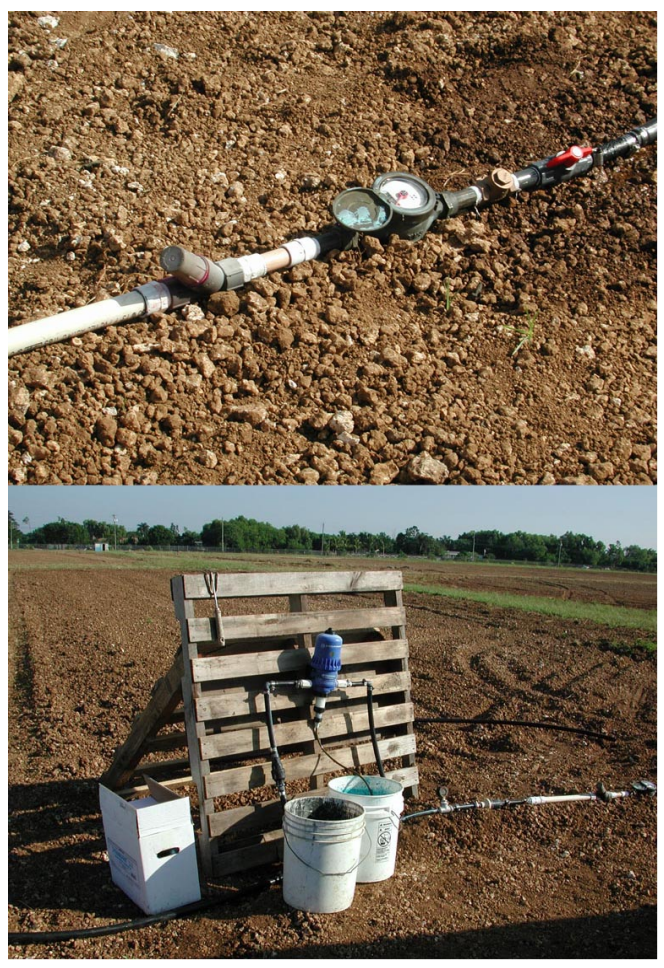

Figure 1. Injection system used for the dye test on a Krome very gravely loam at the Tropical Research and Education Center in Homestead, FI.

The dye test consisted of injecting the dye, irrigating with selected volume of water, digging longitudinal and transverse of the raised beds, and taking measurements. After pressurizing the irrigation system, a blue dye (Brilliant Blue CF, Terramark SPI High Concentrate, ProSource One, Memphis, TN) was injected at a 1:49 (v:v) dye:water dilution rate for the first $30 \mathrm{~min}$. and at the 1:100 dilution rate thereafter. Diluted dye, instead of clear water, was injected after the initial dye injection to prevent losing the water front.

Digging was done immediately after completion of the test. For each treatment, a 4-ft-long and two transverse sections were dug, which allowed measurements to be taken on several emitters. The shapes of the wetted zones were described qualitatively and quantitatively. Wetted zones were described as round (circular), elongated (true elliptic), rectangular (modified elliptic shapes due to the joining of the wetting pattern of two adjacent emitters), or irregular (when none of the above 
descriptions applied). For the quantitative description of the zone, depth, width and length were measured under each emitter as the longest vertical length from the drip tape to the bottom of the blue ring, the horizontal length perpendicular to bed axis at the widest point of the wetted zone, and the horizontal length parallel to the bed at the widest point of the wetted zone, respectively. Actual measurements were converted into relative wetted measurements based on the greatest possible wetted lengths by bed width for width (32 inches), soil depth for depth (7 to 10 inches in this field), and emitter spacing for length.

\section{Soil Moisture and Redistribution Patterns Described Under Rocky Soils Plastic Mulched Beds}

Because initially concentrated dye was injected followed by diluted dye, the dye patterns in the soil profile appeared as a 1-inch-thick blue ring surrounding a lightly colored section of soil. The dye was easily distinguished in the soil, but the contrast between the soil color and the blue ring was increased by allowing a 1 - to 2 -hr. drying period after digging.

All the wetted zones were irregular in shape for all flow rates and length of irrigation (Fig.2 next page).

Gravelly textured soils are difficult to pack during bed formation, and water may flow along soil particles. Irregular shapes such as the ones observed on the Krome very gravelly loamy soil are in contrast with those observed on sandy soils (Fig. 3), which tended be round to elongated in the absence of an impermeable layer (Simonne et al., 2003).

Increasing injection volume from 21 to 142 $\mathrm{gal} / 100 \mathrm{ft}$ did not have a practical effect on depth, and length of the wetted zone as all measurements ranged between 3.8 and 8.0 inches. For each drip tape, increasing injection volume significantly increased wetted width, only within the narrow 4- to 9-inch range. After 2 to $3 \mathrm{hrs}$. of irrigation, the dye reached the calcium carbonate bedrock and moved into it thereafter.

Once water reaches the bed rock, it becomes decreasingly available to the plant because roots

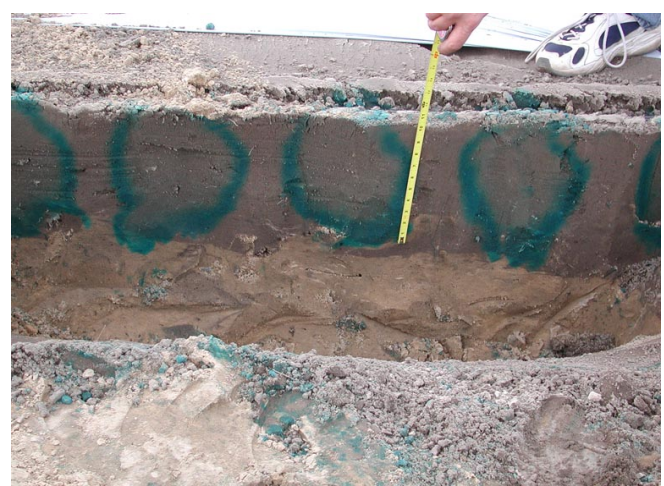

Figure 3. A wetted zone after $1 \mathrm{hr}$ irrigation using a 24 gal/100ft/hr drip tape (Roberts) on a Lakeland fine sand near Live Oak, Fl.

poorly colonize the bedrock. Water and soluble nutrients are likely to decrease shallow ground water quality once they enter the bedrock. Hence, irrigation length should maintain water in the loose section of the profile and above the bedrock. Wetted bed width ranged only between 4.5 and 8 inches and illustrates poor lateral movement of water on coarse-textured soils in the absence of an impermeable layer. Poor lateral movement seldom affects crop water uptake since seeds or transplants are usually placed within inches of the drip tape. The most important implication of a limited lateral water movement is for fumigant application and distribution. Total bed wetting is necessary for the uniform application of fumigants that stay in the water phase such as potassium N-methyldithiocarbamate (K-Pam) and sodium $\mathrm{N}$-methyldithiocarbamate (VaPam). These results support the need for narrow beds and/or multiple drip tapes per bed when complete bed wetting is needed (Table 2).

Complete emitter-to-emitter coverage was observed after one hour of irrigation for the tapes with 4- or 8-inch emitter spacing. The highest wetted length for the tapes with 12-inch emitter spacing was 8 inches, suggesting incomplete coverage when 12-inch emitter spacing is used.

\section{References}

Clark, G.A. and A.G. Smajstrla. 1993. Application volumes and wetting patterns for scheduling drip irrigation in Florida vegetable production. Fla. Coop. Ext. Serv. Circ. 1041, U. of Florida, Fla. 


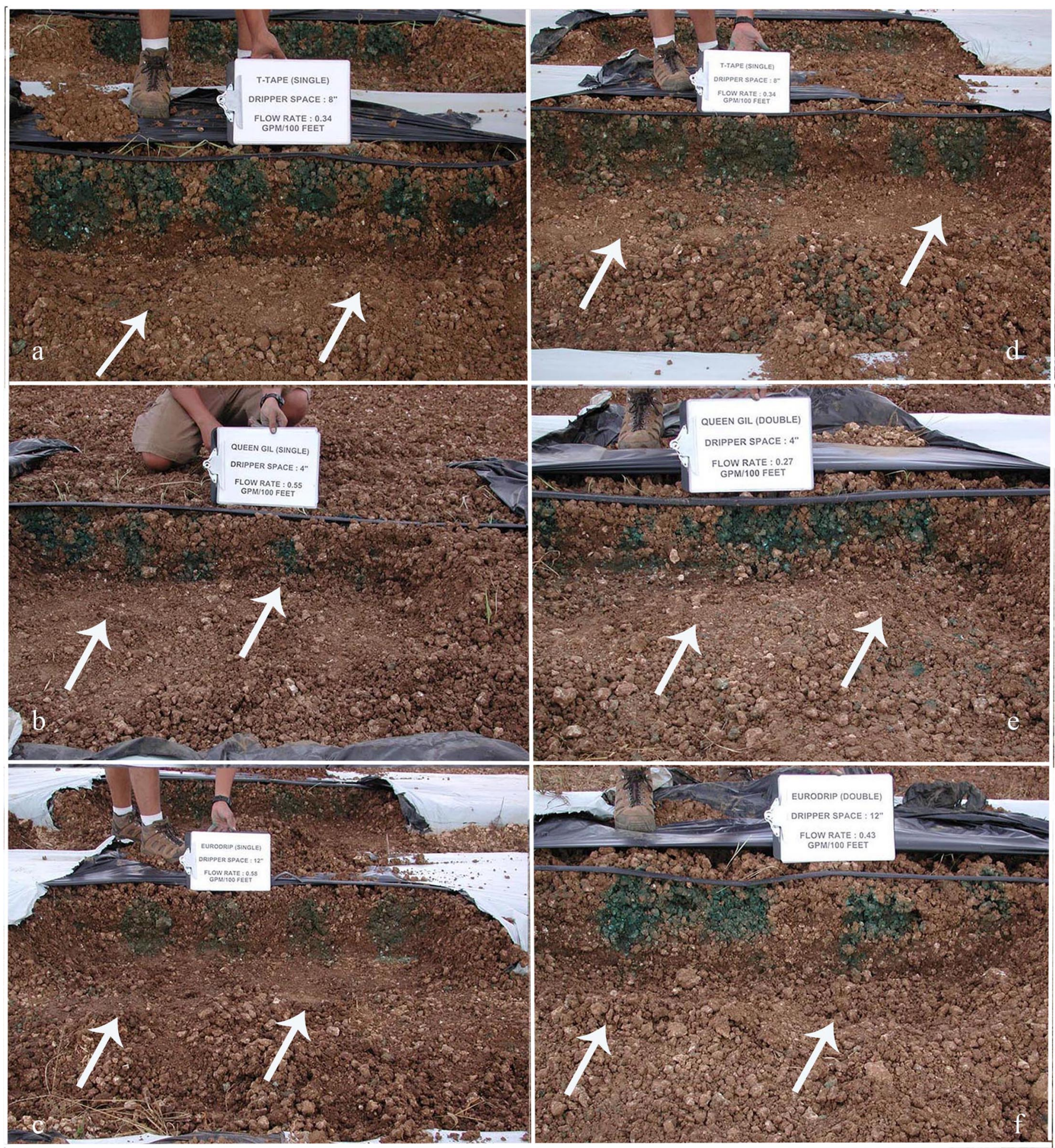

Figure 2. Shape of wetted zone observed on longitudinal sections of a 7 to 10 inch deep Krome very gravely loam at the Tropical Research and education Center in Homestead, Fl for selected drip tapes: T-Tape (1 hr. - a -, 2 hrs -b-), Queen Gil (1 hr. -c- and -d-), and Euro drip ( $2 \mathrm{hr}$. -e- and $3 \mathrm{hr}-\mathrm{f}-$ ). Note that the arrows in the pictures point to the dye. 
Degner, R.L., T.J. Stevens, and K.L. Morgan. 2001. Miami-Dade agricultural land retention Summary and recommendations, vol. 1, Fla. Agri. Market Res. Center, ISA, Univ. of Gainesville, 89 pp.

German-Heins, J. and M. Flury. 2000. Sorption of brilliant blue FCF in soils as affected by $\mathrm{pH}$ ionic strength. Geoderma 97:87-101.

Li, Y.C. 2001. Calcareous soils in Miami-Dade county. EDIS Fact sheet SL183, http://edis.ifas.ufl.edu/TR004.

Li, Y.C., H.H. Bryan, W. Klassen, M. Lamberts, and T. Olczyk. 2002. Tomato production in Miami-Dade county, Florida. EDIS HS-858, http://edis.ifas.ufl.edu/TR014.

Muñoz-Carpena, R., M.D. Dukes. 2005. Automatic Irrigation Based on Soil Moisture for Crops. EDIS Fact Sheet ABE356, http://edis.ifas.ufl.edu/AE354.

Olczyk, T.W., Y. Li, and R. Munoz-Carpena. 2002. Using tensiometers for vegetable irrigation in Miami-Dade county. EDIS Fact Sheet ABE326, http://edis.ifas.ufl.edu/TR015.

Simonne, E.H., M.D. Dukes, and D.Z. Haman. 2004. Principles and practices for irrigation pp. 33-39 In: S.M. Olson and E. Simonne (Eds.) 2003-2004 Vegetable Production for Florida, Vance Publishing, Lenexa, KS.

Simonne, E.H., D.W. Studstill, R.C. Hochmuth, G. McAvoy, M.D. Dukes and S.M. Olson. 2003.

Visualization of water movement in mulched beds with injections of dye with drip irrigation. Fla. State Hort. Soc. 116:88-91. 
Table 1. Selected drip tapes used for the dye test on a Krome very gravelly loam soil in Homestead, Fl.

\begin{tabular}{||c|c|c|c||}
\hline \hline \multicolumn{2}{|c|}{ Flow Rate } & \multicolumn{2}{c||}{ Drip Tapes Used } \\
\cline { 2 - 4 } & Range (gal/hr/100ft) & $\begin{array}{c}\text { Flow Rate } \\
\text { (gal/hr/100ft) }\end{array}$ & $\begin{array}{c}\text { Emitter Spacing } \\
\text { (in) }\end{array}$ \\
\hline Class & \multirow{3}{*}{ High Flow } & $33^{\mathrm{a}}$ & 4 \\
\hline \multirow{2}{*}{ Medium Flow } & \multirow{2}{*}{20 - 30 } & $35^{\mathrm{b}}$ & 12 \\
\cline { 3 - 4 } & & $21^{\mathrm{c}}$ & 12 \\
\hline \multirow{2}{*}{$\begin{array}{c}\text { a) Manufacturer; Queen Gil. b) Manufacturer; Eurodrip. c) Manufacturer; T-Tape. d)Manufacturer; Aquatraxx. e) } \\
\text { Manufacturer; Netafim. }\end{array}$} \\
\hline \hline
\end{tabular}

Table 2. Expected wetted width and corresponding injection irrigation volume for different drip tape and flow rate classes in a Krome very gravelly loam soil in Homestead, Fl.

\begin{tabular}{|c|c|c|c|}
\hline Number of drip tape & Flow rate class & $\begin{array}{l}\text { Expected total wetted } \\
\text { width (in) }\end{array}$ & $\begin{array}{l}\text { Irrigation volume for } 2 \mathrm{hr} \\
\text { irrigation } \mathrm{x} \\
(\mathrm{gal} / 7,260 \mathrm{lbf} / 2 \mathrm{hr})\end{array}$ \\
\hline \multirow[t]{3}{*}{1} & High & $5-8$ & 2,200 \\
\hline & Medium & $5-8$ & 3,600 \\
\hline & Low & $5-8$ & 5,100 \\
\hline \multirow[t]{3}{*}{2} & High & $10-16$ & 4,400 \\
\hline & Medium & $10-16$ & 7,300 \\
\hline & Low & $10-16$ & 10,200 \\
\hline \multicolumn{4}{|c|}{$\begin{array}{l}\text { zTapes spaced } 10 \text { inches apart. } x \text { Using the median values of } 15,25 \text {, and } 35 \mathrm{gal} / \mathrm{hr} / 100 \mathrm{ft} \text { for low, medium, and high } \\
\text { flow rate respectively. } \mathrm{x} \text { acre planted field on } 6 \mathrm{ft} \text { bed spacing assuming } 100 \% \text { delivery efficiency. }\end{array}$} \\
\hline
\end{tabular}

